\title{
Risk Utilization in Quantitative Approach
}

\author{
Gowtham Kumar Pullagujju1)
}

\begin{abstract}
The evaluation of general remaining danger is the essential target of performing danger administration exercises and is required by the given medical device - Application of Risk Management to restorative Devices. Regardless of this prerequisite, much disarray stays among medical - device makers and the different administrative endorsement bodies in the matter of what is required. Today, numerous medicinal gadget producers don't formally address the subject. This paper will address the is general lingering danger of the medicinal gadget and Why is general remaining danger the most vital measure of security all through the item life cycle and How can general leftover danger be evaluated and we can locate a satisfactory level of general estimate danger and how the general estimating the danger used to oversee wellbeing after the item has discharged This will give sense thoughts that will permit therapeutic - device makers to start surveying the general lingering danger of their items, and may likewise be useful to administrative bodies in figuring and imparting a steady arrangement of desires and by the device hazard administration we will discover the how the restorative gadgets remaining danger can be assessed.so that the product produced is more reliable.
\end{abstract}

Keywords : evaluation, therapeutic, endorsement, lingering, imparting

\section{Introduction}

Now-a-days, we are expericing serious problems in evaluation of risk the medical devices that the devices have many individual risks which for the devices we will find the risk residual risk and we summarize first we will find the individual risks and we will find overall residual risk of the device and then we will calculate wheather the hazard can be reduced or not we should add some scenarios to the existing hazard so that the risk to the system is reduced such that risk is minimized in the system (or) the product[1-3].

Generally residual risk is the threat that remains after all the efforts that are risk is eliminated we can deal the risk to we can reduce risk, avoid it, accept it, transfer it into these different ways such that residual risk is reduced[4-6].

Residual risk cannot be unknown to organizations generally they prefer to accept residual

Received(February 04, 2015), Review Result(1st: February 17, 2015, 2nd: March 9, 2015), Accepted(March 10, 2015)

${ }^{1}$ (Corresponding Author) Vidyaa Vikas Educational Institutions, Mysore - Bannur Road, Alanahally, Mysuru, Karnataka, India

email: pullagujjugowtham@gmail.com 
risk or to transfer it. When we are taking about the residual risk organization should have to identify relevant governance rand compliance requirements and they should determine the organization control frame works strength and weakness and oraganizations should acknowledge the existing risks and to identify some ways in offsetting the unacceptable residual risks.

\section{Rationale}

The field that we have choosen is software engineering. The use of software engineering in very important in the development of any software[7-9]. In the Risk analysis for the given product so that more reliability to the device in this we From an abstract diagram comes about that the measurement of the likelihood of event of the blunder by the client is basically tended to with in the atomic field, where a conceivable blunder could bring about intense outcomes of a to a great degree huge number of individuals. By the by, studies concerning HRA can be discovered likewise in the Industrial Process Avionics, Railroad With respect to etting field the fundamental HRA-procedures utilized are: FTA, FMEA/FMECA, THERP, RCA CREAM, HCR and TESEO yet, there is nobody think about that worries the assessment of human unwavering quality in the particular utilization of restorative gadgets[10]. Thus what's more, considering that none of these just said strategies fit totally to our application, we chose to propose another procedure, based on information and methodologies from literature, to assess the risk linked to the human factor in the use of medical devices in the real world we much find some new process in finding out the development life cycle of the product and we should have to more adaptive to the scenario.

The Human Reliability Analysis (HRA) intends to distinguish the potential disappointment of the framework coming about because of human mistakes, break down reasons and distinguish suitable countermeasures to anticipate and diminish however much as could reasonably be expected the connected danger. Human blunders have an effect somewhere around $60 \%$ and $90 \%$ of all mishaps in industry and transport. Considering that people are included in all life cycle periods of a framework could be identified with human mistake or insufficient choices in a prior stage. This study proposes a strategy to assess the danger related to the particular utilization of health devices

\section{Problem Statement:}


Now a Days in the medical devices the risk is more and we should have a device development life cycle before the product is being implemented and we should be have all the prerequisties for the development of the product and we should reduce the hazards to the system and to reduce the residual risk we should have to find the individual risks to the product and we should have to make add the individual risks such that the risk is reduced and the residual risk that we find should and we should be less that according to the software development life cycle process.

We should calculate the some scenarios existing to the device and we should act quantitatively depending on the situation and we should be able to do the process and we should reduce the residual risk of the device and some techniques like FMEA (Failure Mode and Effect Analysis ) in this we find the RPN (Risk Priority Number ) and we will take the action to the system and we will reduce the risk to the device and we should analyze according to the previous individual risks and we should reduce the risk and we should act accordingly and we should act and reduce the risk and we can make necessary actions to the analysis answer should find the new apporach in finding the medical device by adding all the scenarios and we should reduce the risk to the device and make the device more reliable and give more service to the users for that we shold have application development process .

\section{Basic Description:}

Governments practice their obligation to look after request in the public arena by a wide assortment of means, one of which is the advancement and implementation of regulations to prepare for dangerous the most items. In today's reality, one of the ways this has been proficient is through the arrival of ISO 14971:2000. Consistence to this standard is required to offer The most gadgets in Europe, Canada, and Australia. Inside the United States, the standard is perceived by the FDA as an approach to meet the goal of the Quality System Regulation prerequisites for the improvement of safe restorative items. Lamentably, capable associations frequently go overboard to these sorts of regulations, despite the fact that they don't have anything to dread from the legislatures included, and make excessively exquisite Further more, point by point forms that they can't essentially take after. Inside consistence reviews that attention on the minutia and not the huge picture regularly fuel the issue and 
prompt more, not less, handle prerequisites. Humorously, the net result is that the association can cause harm with an administrative body, not with standing their introductory great goals, in light of the fact that they are not able to take after their own procedure. The accompanying rules are a beginning stage for coordinating a commonsense danger administration process into your general advancement process.

1) Detailed procedures work best when you are attempting to precisely replicate a thing (assembling) or counter balance a absence of ability. Item improvement is the inverse of this. You can get a reliable feast at your most loved fastfood eatery, yet in the event that you truly need an incredible feast, you go to an eatery with a culinary expert who does not utilize an off-the-rack cookbook! The culinary expert's feast is undifferentiated from item advancement: Product improvement tries to make remarkable novel item outlines utilizing exceptionally talented individuals. It is more about craftsmanship than creation. Consigning item improvement to an excessively point by point procedure will probably accomplish unremarkableness (or more terrible) than magnificence by smothering imagination. An excessive amount of subtle element is

especially risky when security is included. Dependence on an agenda mindset can prompt lamentable results at the point when security issues with another item don't fall conveniently into the agenda.

Too much process subtle element prompts an extravagant number of assignments and deliverables that requires the consumption of over the top assets to track progress against the undertaking plan. An excess of steps avoid the associations vitality far from fundamental exercises. Ask of each procedure step in the event that it includes any worth.

On the other hand, too little process prompts disarray inside of the improvement group as it scans for the privilege blend of deliverables to fulfill administrative bodies. Startup associations with leap forward advances drove by a visionary identity or introductory endeavors of a full grown association at outsourcing outlines are especially powerless to having too little process.

The perfect procedure ought to give just a system and empower you to report what you do in an arrangement and words that reflect the material regulations and guarantee that quality, administrative, and business needs are met. Associations must discover the equalization point between seeing the comprehensive view, while including enough detail to guarantee consistency and productivity in conveying the task to a effective conclusion. Composing such a procedure requires a mix of visionary and conscientious identities.

Completeness of danger assessment : 
The maker might guarantee that the risk(s) from all distinguished perils have been assessed. The consequences of this evaluation might be recorded in the danger administration document. Overall leftover danger assessment After all danger control measures have been executed what's more, confirmed, the producer should choose if the generally speaking lingering danger postured by the restorative gadget is satisfactory utilizing the criteria characterized in the danger administration arrangement. On the off chance that the general lingering danger is judged inadmissible utilizing the criteria built up in the danger administration arrange, the producer should accumulate and survey information and writing on the restorative advantages of the proposed use/planned reason to figure out whether they exceed the general leftover danger. In the event that this proof does not bolster the conclusion that the health advantages exceed the general lingering danger, then the danger stays inadmissible. The consequences of the general remaining danger assessment might be recorded in the danger administration document.

If the potential danger occasion shows up in the low district, it should be anticipated after some sensible steps or some measures ought to be taken to decrease its negative effects. In the danger measurements chart, in light of the fact that there is no thought to the change from vulnerabilities, the danger appraisal is just staying at subjective level. So as to consider the danger level from quantitative perspective, this study takes FMEA as a helpful technique to assess dangers and at that point figure out the basic abnormal state hazard in the evaluating process. At the point when a danger occasion is identified, the inquiry concerning how to decide the level of it gets to be basic. As indicated by ISO14971 of therapeutic gadget [9], danger is depicted as an item of two segments, to be specific the probability that a danger will happen what's more, the seriousness of that hazard if it really happen. What's more, the conditions of peril seriousness are grouped into a few discrete levels: basic, moderate, ignorable; and the conditions of peril probability are grouped into a few discrete levels: high, center, low. On the premise of this system, seriousness and probability can be served as x-axis and yaxis and y-hub to build hazard measurements, which is appeared in the diagram.

From the beneath outline The significant procedure of FMEA method The use of FMEA in danger administration has fourbasic stages to perceive danger level. On the premise of security learning of therapeutic gadget, the seriousness, event and discovery of every disappointment can be esteemed by FMEA technique withthese steps that incorporate recognizing potential outcome, distinguishing potential cause and recognizing accessible procedure control to verify the RPN number for the disappointment, which is appeared in Fig.4. Keeping in mind the end goal to get quantitative information for the three records over, every list can be isolated into 
ten levels from 1 to10 as indicated by disappointment assessment criteria. By and by, withthe same model, assessment framework don't generally receive ten-level framework, however the framework with different sorts of levels like $1,3,5$ or 2, 4, 6, 8 is additionally possible. In the wake of assessing potential disappointment mode for every danger, the RPN number can be resolved and bigger RPN number speaks to higher danger level and activity need. As is underneath figure this paper takes therapeutic device product as an application sample. Every sort of danger amid the lifecycle may happen or recognized before happening. At that point FMEA can be utilized to dissect the disappointment methods of danger occasions keeping in mind the end goal to verify the RPN quantities of them which are taken as the measure to decide the need levels. For this situation if the RPN number goes past adequate level, the comparing danger occasion must be relieved by accessible measures, or else the danger occasion simply should be under checking. After that, abnormal state perils are clarified easily. During the lifecycle of medicinal gadget item, if the RPN level of a disappointment mode is higher than that of others, it demonstrates event of the reason, seriousness or discovery of the disappointment may be higher than that of others, and this disappointment occasion ought to be taken as the key purpose of danger management. So, it is huge to ensure the need levels of dangers for therapeutic gadget through FMEA system keeping in mind the end goal to focus on the abnormal state danger to dodge the pointless misfortune and improve the reliability of the device.

\section{Conclusion}

We should find the residual risk by many study cases for the scenario and from the scenario we should reduce the risk in the manufacturing process. Risk management is an ongoing process that is implemented as part of the initial project planning activities and utilized throughout all of the phases of the software development lifecycle. In product development we should reduce the harm to the system and the residual risk of the product is minimized by adding different scanarioes. The proposed strategy can be utilized to look at the level of danger connected with human blunder for two or more restorative gadgets. The data that can be drawn from the utilization of the method are danger record, so it can be viewed as a semi-quantitative method. The technique does not give a result regarding likelihood of blunder. Keeping in mind the end goal to upgrade the capacity of danger distinguishing proof and assessment for medicinal gadget, this paper applies the system for FMEA to the danger 
administration of item. We find the RPN value and find out the risk of individual risks to the complete risks by this we can reduce the risk and increase the quality of the product which is reliable.

\section{References:}

[1] X. Zhao and X. Bai, The Application of FMEA Method in the Risk Management of Medical Device during the Lifecycle, e-Business and Information System Security (EBISS), 2010 2nd International Conference on, (2010) May 22-23; Wuhan, China

[2] M. Catelani, Risk assessment in the use of medical devices a proposal to evaluate the impact of the human factor, Medical Measurements and Applications (MeMeA), 2014 IEEE International Symposium on, (2014) June 11-12; Lisboa, Portugal

[3] Catalão-Lopes, M., Bank mergers, information, default and the price of credit, Economic Notes, (2006), Vol.35, No.1, pp.49-62.

[4] K. K. Lewis, Why do stocks and consumption imply such different gains from international risk sharing?, Journal of International Economics, (2000), Vol.2, No. 1, pp. 1-35.

[5] S. Athanasoulis amd E. van Wincoop, Risksharing within U.S. states: what do financial markets and fiscal federalism accomplish, Review of Economics and Statistics, (2001), Vol.83, No.4, pp. 688-698.

[6] F. I. Khan and M. M. Haddara, Risk-based maintenance (RBM): a quantitative approach for maintenance/inspection scheduling and planning, Journal of Loss Prevention in the Process Industries, (2003), Vol.16, No.6, pp.561 - 573.

[7] P. L. Thomas, Adventures in genre! : rethinking genre through comics/graphic novels, Journal of Graphic Novels and Comics, (2011), Vol.2, No.2, pp.187-201.

[8] J. Hagedoorn, Understanding the rationale of strategic technology partnering: Nterorganizational modes of cooperation and sectoral differences, Strategic Management Journal, (1993), Vol.14, No.5, pp.371-385.

[9] Six Sigma, https://www.isixsigma.com, March 21 (2014).

[10] Egerton Consulting, http://egertonconsulting.com/, March 21 (2014). 